\title{
PRECISAMOS FALAR SOBRE A BIOÉTICA E A BIOIMPRESSÃO DE ÓRGÃOS
}

3D

\author{
Daniela Nicolai de Oliveira Lima* \\ Denise Schmitt Siqueira Garcia*
}

\section{RESUMO}

$\mathrm{O}$ artigo aborda o problema referente à fila de espera por transplantes de órgãos no Brasil e propõe como solução a bioimpressão de órgãos 3D. O professor italiano Stefano de Rodotá aprofundou-se na bioética e nas teorias do transumanismo e do pós-humanismo, afirmando que o homem desenvolverá suas capacidades físicas e mentais, com o auxílio da ciência, para um novo patamar de evolução antropológica. Assim, deve respeitar-se o seu direito de autodeterminação, sobre seu corpo e sua existência, com base no princípio constitucional da dignidade da pessoa humana. A metodologia é indutiva, através da pesquisa bibliográfica qualitativa, pela via eletrônica.

Palavras-chave: Bioética. Bioimpressão 3D. Transplante de Órgãos. Transumanismo e Póshumanismo.

\section{ABSTRACT \\ WE NEED TO TALK ABOUT BIOETHICS AND 3D ORGAN BIOPRINTING}

The article addresses the problem related to the waiting list for organ transplants in Brazil and proposes the solution of 3D organ bioprinting as a solution. Italian professor Stefano de Rodotá went deeper into bioethics and the theories of transhumanism and post-humanism, stating that man will develop his physical and mental capacities, with the help of science, to a

1 Mestranda da Univali-SC, em convênio com a Faculdade Católica de Rondônia. Promotora de Justiça do Ministério Público de Rondônia. Membro da Associação Nacional do Ministério Público do ConsumidorMPCON. Bacharel em Direito pela Universidade Federal de Rondônia. Pós-graduada em Direito do Consumidor pela Universidade Anhanguera-Uniderp/SP. Endereço: Universidade do Vale do Itajaí/SC. Email: nicolai.mpro@gmail.com.

2 Doutora pela Universidade de Alicante na Espanha. Mestre em Derecho Ambiental y Sostenibilidad pela Universidade de Alicante, na Espanha. Mestre em Ciência Jurídica. Especialista em Direito Processual Civil, Graduada em Direito. Atualmente é professora do Programa de Pós Graduação Strictu Sensu em Ciência Jurídica, de pós graduação latu sensu e da graduação da Universidade do Vale do Itajaí. Membro do Grupo de Pesquisa Estado, Direito Ambiental e Transnacionalidade. Advogada. Endereço: Universidade do Vale do Itajaí/SC. E-mail: denisegarcia@ univali.br. 
new level of anthropological evolution. Thus, their right to self-determination, regarding their body and their existence, based on the constitutional principle of human dignity, must be respected. The methodology is inductive, through qualitative bibliographic research, electronically.

Keywords: Bioethics. 3D Bioprinting. Organ Transplantation. Transhumanism and Posthumanism. 


\section{INTRODUÇÃO}

O presente artigo teve como objetivo geral estudar a obra do professor italiano Stefano de Rodotá, no que diz respeito ao desenvolvimento do conceito de autodeterminação do indivíduo, sobre a sua existência (o direito de nascer e morrer) e o seu corpo (uso de próteses), que possui relação com o princípio fundamental da dignidade da pessoa humana, previsto no art. $1^{\circ}$, inciso III, da Constituição Federal de 1988 (BRASIL, 1988).

Diante dos avanços científicos e tecnológicos da pós-modernidade, o indivíduo deve ter a liberdade de eleger as intervenções médicas a que pretende se submeter, em vida, como no caso do uso de próteses, que melhoram sua qualidade de vida, nelas se enquadrando os órgãos 3D, feitos em laboratório, que prolongam artificialmente a vida, ou post mortem, como no caso do consentimento do paciente, que se declara doador de órgãos, para autorização posterior de sua família, sobre a doação de seus órgãos.

O problema que norteou a pesquisa foi a constatação de que milhares de pessoas aguardam por transplantes de órgãos no Brasil, situação que se agravou com a Covid-19, fazendo-se necessário quebrar o tabu sobre a doação de órgãos, pois muitas famílias ainda resistem em autorizar a retirada dos órgãos, após a morte encefálica do paciente.

Como solução, propusemos a bioimpressão de órgãos 3D, tecnologia que ainda se encontra em fase de desenvolvimento, com previsão de que, nos próximos 20 anos, já haverá órgãos humanos artificiais disponíveis ao público. Essa tecnologia se encaixa no conceito de prótese, constitutiva de um indivíduo trans-humano, com partes biológicas e outras artificiais, mas com melhor qualidade de vida e com potencial de prolongamento artificial da vida, conforme defendido pelo professor Rodotá.

O artigo é dividido em três momentos: no primeiro, trazemos a retrospectiva da obra de Rodotá, destacando suas ideias principais, inicialmente, sobre a proteção da intimidade dos dados pessoais na Internet e a Inteligência Artificial. Depois, sobre os conceitos de bioética, transumanismo e pós-humanismo. No segundo, adentramos na questão dos transplantes de órgãos no Brasil, notadamente quanto à grande demanda por transplantes e o reduzido número de doadores. No terceiro, buscamos propor como solução, a bioimpressão de órgãos 3D, que já é objeto de pesquisas científicas desenvolvidas em vários países do mundo, inclusive no Brasil.

Para este estudo, a metodologia utilizada foi de natureza indutiva, utilizando-se de fonte secundária, a partir de pesquisa bibliográfica qualitativa, pela via eletrônica, através da 
revisão de artigos científicos publicados e reportagens sobre os temas abordados.

\section{A importância da obra de $\operatorname{Rodotá}^{3}$ para compreender a pós-modernidade}

O pensamento do professor italiano Stefano de Rodotá, traduzido em diversos textos e palestras, traz uma profunda reflexão sobre a revolução tecnológica e científica do século XXI e suas implicações na vida dos indivíduos e no direito contemporâneo. O que chama a atenção na obra de Rodotá é o fato de que o autor nasceu em 1933, pouco antes do início da Segunda Guerra Mundial, e, durante toda a sua vida, de quase um século (pois veio a falecer em 2017), manteve vasta produção intelectual e ativa vida acadêmica, adentrando em temas de vanguarda, como a Internet, a bioética, o transumanismo e o pós-humanismo.

Diante da relevância de sua obra, traçaremos uma retrospectiva da mesma, destacando os principais pontos do seu pensamento, inicialmente sobre a nova realidade tecnológica criada pela Internet e a necessidade de proteção da intimidade dos dados pessoais ali compartilhados e posteriormente, sobre a bioética, em face dos avanços da Ciência e da Medicina.

\subsection{A Revolução Tecnológica}

Na década de 70, a atenção de Rodotá se voltou à expansão dos computadores e processadores de dados, a chamada "revolução tecnológica", e seus reflexos na vida das pessoas, promovendo discussões sobre a "democracia eletrônica", numa antecipação dos debates sobre cidadania em rede, tão em voga hoje (DONEDA; ZAMATTA, 2017, p. 03).

Já, naquela época, Rodotá falava em uma "hiperdemocracia", onde os conceitos tradicionais de soberania, jurisdição e cidadania seriam relativizados e redefinidos pelas possibilidades tecnológicas, antevendo o movimento do direito transnacional.

Em 1973, publicou o livro Elaborati elettronici e controllo sociale, que estabelecia os parâmetros para que o conceito de privacidade fosse reformulado, conectando-o aos princípios democráticos e liberdades civis, diante da necessidade de "controlar como outros utilizam informações sobre você" e não meramente em seu aspecto individualístico, ligado ao tradicional conceito de Warren e Brandeis de privacy, como "direito de ser deixado só"

3 RODOTÁ, Stefano. Il diretto di avere diritti. Roma-Bari, Laterza, 2012. ISBN 978-88-420-9608-5. 
(DONEDA; ZAMATTA, 2017, p. 04).

Em parceria com Vittorio Frosini, Rodotá desenvolveu o conceito de "direito da tecnologia", refletindo sobre como o uso massivo de computadores servia de instrumento de controle da vida privada, que, no Brasil, inspirou a criação de uma ação constitucional (Habeas Data ${ }^{4}$, visando o maior controle do cidadão sobre seus dados pessoais. Liderou o movimento de "constitucionalização da Internet", incentivando o caráter aberto e inclusivo da rede mundial de computadores, contra tendências capazes de subvertê-lo e transformá-lo em espaço controlado, com a tendência de vigilância e monitoramento.

Em palestra conferida no Rio de Janeiro (2003) já afirmava que "nós somos os nossos dados", pois nossa representação social é cada vez mais confiada a informações espalhadas numa multiplicidade de bancos de dados e perfis, construídos por sujeitos públicos e privados, por meio dos dados que nos dizem respeito, fazendo-se necessária a tutela desse “corpo eletrônico" (RODOTÁ, 2003, p. 3).

No evento Internet Governance Forum (ONU, 2006) liderou uma coalização para debater o conteúdo da Carta de Direitos para a Internet (Internet Bill of Rights), servindo como ponto de partida para o Marco Civil da Internet do Brasil (Lei n 12.965/2014) e para a Declaração de Direitos na Internet, editada pelo Parlamento Italiano, em 2015.

Rodotá foi um visionário, que já previa a terceira onda da Internet (ou Internet 3.0), ao falar de "tsunami digital", que hoje ameaça os direitos fundamentais de privacidade, identidade e liberdade das pessoas, na medida em que a máquina substitui a autonomia humana, através de programas que autogerenciam, fornecendo respostas e satisfazendo exigências (RODOTÁ, 2012. p. 325). Conforme Siqueira (2020, p. 2), essa realidade está cada vez mais próxima, com o desenvolvimento da Inteligência Artificial (IA), havendo previsões no sentido de que, em poucos anos, a máquina substituirá o ser humano na tomada de decisões, inclusive judiciais, estruturadas a partir de uma base de dados e de aprendizado da máquina, fazendo operações algoritmas, aproximadas às do cérebro humano, com autonomia de ação.

Esse assunto foi objeto, recentemente, de um documentário chamado "O Dilema das Redes", de Trinstan Harris (disponível na Netflix), onde o ex-consultor ético do Google

4 Art. $5^{\circ}(\ldots)$ LXXII - conceder-se-á habeas data: a) para assegurar o conhecimento de informações relativas à pessoa do impetrante, constantes de registros ou banco de dados de entidades governamentais ou de caráter público. b) para retificação de dados, quando não se prefira fazê-lo por processo sigiloso, judicial ou administrativo (Constituição da República Federativa do Brasil, de 05 de outubro de 1988. - Brasília: Senado Federal, Subsecretaria de Edições Técnicas, 2008, 464 p.) 
denuncia a manipulações dos dados pessoais e dos padrões de comportamento dos usuários, pela rede mundial de computadores, através da Inteligência Artificial, com consequências nefastas para a intimidade das pessoas.

Assim, a primeira parte da obra de Rodotá merece destaque, por sua relevância para o desenvolvimento de um sistema de proteção à intimidade dos dados pessoais dos internautas, em face da sua comercialização e uso indevido, pelos macrocomputadores que operam na Internet.

\subsection{A Revolução Científica}

\subsubsection{Da bioética e da autodeterminação do indivíduo}

Em seu livro, Il diritto di avere diritti, Rodotá adentra em outro tema de vanguarda no qual passaria a trabalhar: a bioética. Para ele, a palavra "biologia" se tornou o molde para outros ramos da ciência: "biopolítica", "bioética", "biodireito". Em seguida, aparecem a "biocidadania de direitos" e a "biocidadania digital" e, acima de tudo, o "bioconstitucionalismo".

A Bioética é o estudo transdisciplinar entre as Ciências Biológicas, Ciências da Saúde, Filosofia (Ética) e Direito (Biodireito), que investiga as condições necessárias para uma administração responsável da vida humana, animal e ambiental. Considera, portanto, questões onde não existe consenso moral, como a fertilização in vitro, o aborto, a clonagem humana, a eutanásia, os alimentos transgênicos e as pesquisas com células-tronco, bem como, a responsabilidade moral de cientistas em suas pesquisas e aplicações na área da saúde (DINIZ \& GUILHEM, 2002).

Rodotá afirma que há uma crescente "juridicização da sociedade”, que invade os "mundos vitais", limitando a liberdade de escolha individual, em matérias que deveriam ser reservadas à decisão autônoma das pessoas, pois dizem respeito à existência humana, à personalíssima forma de entender a vida, como "o direito de nascer e morrer", firmando um posicionamento bastante liberal, ligado ao direito de autodeterminação do indivíduo, como direito fundamental da pessoa humana. Afirma que deve haver uma distribuição de poderes na relação médico-paciente, quanto à tomada de decisões, que atingem a esfera biológica do indivíduo, mediante o consentimento informado (RODOTÁ, 2012. p. 337).

5 Proprio la parola 'biologia" é divenuta il calco al quale si sono riferite nel loro divenire scienze antiche: e cosi discutiamo di "biopolítica", "bioética", "biodiritto". Compaiono poi la "biocittadinanza dei diritti" e a "biocittadinanza digitale" e, soprattutto, il "bioconstituzionalismo" (RODOTÁ, S., 2012. p. 252). 
Para o professor, a autodeterminação do indivíduo, sobre sua vida e seu corpo, representa o ponto mais intenso e extremo da liberdade existencial, o que corresponde ao princípio constitucional da dignidade da pessoa humana, presente no artigo $1^{\circ}$, inciso III da Constituição da República Federativa do Brasil (BRASIL, 1988), destacando a questão geral do que pode ser definido como o núcleo regulador da subjugação racionalista moderna (autonomia, autodeterminação, participação), que parecia rejeitada no contexto da pósmodernidade, mas para a qual, precisamente, as novas dimensões do viver e da relativa dinâmica da subjetividade têm atribuído nova legitimidade (Rodotá, 2012, p. 250). ${ }^{6}$

Rodotá defendia que deveria haver um "consenso biográfico" ou testamento do paciente, com base na sua liberdade de autodeterminação, sobre as suas escolhas terapêuticas e os tratamentos médicos a que pretendia se submeter, às suas escolhas de fim de vida, de forma refletida e fundamentada, utilizado não apenas quando a vontade precisa ser reconstruída, mas também quando deve ser interpretada e em todas as fases em que a decisão amadurece, por meio de um relacionamento médico-paciente e do consentimento informado. ${ }^{7}$

Afirma que essas proibições de caráter ético, quanto à autodeterminação do indivíduo, no início ou fim da vida, muitas vezes, violam a dignidade da pessoa humana, pois retiram do paciente o direito de optar por uma morte natural, por exemplo, sem interferências de aparatos tecnológicos, que prolongam artificialmente o processo de morte, sem qualquer perspectiva de cura ou melhora, deixando o paciente em estado vegetativo. Como consequência, surge um verdadeiro "turismo dos direitos", sobretudo no interior da Europa:

um turismo ora abortivo, ora reprodutivo, ora relativo à eutanásia, para fugir das proibições nacionais que impedem a interrupção da gravidez, o acesso das mulheres a determinados tipos de reprodução assistida, a possibilidade do 'suicídio assistido'. Os direitos reprodutivos, o direito de morrer com dignidade induzem procurar lugares onde nascer e morrer estejam em sintonia com as necessidades profundas de cada indivíduo (RODOTÁ, 2003, p. 4).

6 La autodeterminazione nella vita e nel corpo rappresenta il punto piú intenso e estremo della libertá esistenziale. [...]Su questo sfondo si staglia con nettezza la questione generale di quello che si puó definire il núcleo normativo della soggevitá razionalistica moderna (autonomia, autodeterminazione, partecipazione), che sembrava respinto sullo sfondo della post modernitá, ma al quale proprio le nuove dimensioni del vivere e le relative dinamiche della soggettivitá hanno attributo nuova legittimazione. (Cf. RODOTÁ, Stefano. Il diretto di avere diritti. Roma-Bari, Laterza, 2012. ISBN 978-88-420-9608-5. p. 250).

7 Un consenso 'biográfico' é aquello nel quale si rispecchia e si fonda l'autodeterminazione riguardante le scelte terapeutiche o a dare attuazine alle decisioni relative alla fine della vita. Cosi representa non solo quando la volontá debba essere ricostruita, ma pure quando deve essere interpretata e in tutte le fasi in cui la desisione matura attraverso un rapporto con l'altro: che puó essere il medico chiamato a fornire l'informazione riguardante le scelte terapeutiche a dare attuazione alle decisione relative alla fine della vita. (Ibid., p. 274). 
Assim, reinvidica o direito de "viver uma morte de feição humana", que seja digna, rechaçando a "obstinação terapêutica", que corresponde à prática médica, de abuso da “tecnociência”, para estender inútil e desmedidamente o processo de morte.

O professor italiano assinalava que o direito não deve se tornar o instrumento de ideologias e religiões, capaz de impor determinados valores éticos e morais aos indivíduos, retirando-lhes sua liberdade de escolha, sobre temas ligados à sua vida, sua intimidade e seu corpo. As pessoas devem ter liberdade para realizarem sua personalidade, conforme sua consciência e suas convicções de vida. Nisso se incluem temas polêmicos, como o direito ao aborto, à contracepção, à reprodução assistida, à experimentação genética com os embriões, à eutanásia. Assim, o autor refuta a tentativa de um "disciplinamento global autoritário da vida" (RODOTÁ, 2003, p. 3).

Rodotá afirma que

quando se afirma que o direito de recorrer às tecnologias refere-se às decisões relativas a si mesmo e à própria descendência, equiparam-se situações profundamente diferentes entre si. A autodeterminação, ligada ou não ao uso da técnica, deve receber o máximo reconhecimento quando os efeitos das decisões da pessoa se produzem na esfera do interessado. Não é assim, ao contrário, quando se quer construir corpo e vida de outros, violando a sua 'liberdade existencial', protegida pelo seu consentimento, que, portanto, não pode ser substituído pela vontade de outros, sujeitos privados ou poderes públicos (RODOTÁ, 2003, p. 4).

Sobre as escolhas terapêuticas, afirma que, nenhuma vontade externa, mesmo que expressada em coro por todos os cidadãos ou por um Parlamento unânime, pode substituir a da pessoa em questão", pois dizem respeito à esfera íntima do indivíduo, seu corpo e sua existência. Assim, o consentimento informado se baseia na síntese de dois direitos humanos fundamentais: o da autodeterminação e o da saúde. Quando se trata de questões da existência, como nascer e morrer, surge a necessidade de se respeitar a pessoa humana como tal e sua dignidade, uma vez que somos confrontados com o indecidível. ${ }^{8}$

\subsubsection{Do transumanismo e do pós-humanismo}

8 Il punto chiave é il seguente: la circonstanza che il consenso informato trova il suo fondamento neli art. 2 , 133 e 32 della Constituzione [italiana] pone in risalto la sua funzione di sintesi di due diritti fondamentali della persona: quello all' autodeterminazione e quello alla salute. Si coglie qui, nitidamente, una distribuzione di poteri [...]. Quando si giunge al nucleo duro dell' esistenza, alla necessitá di rispettare la persona umana in quanto tale, siamo di fronte all' indecidibile. Nessuna volontá esterna fosse pure quella coralmente espressa da tutti cittadini o da un Parlamento unanime, puó prendere il posto di quella dell' interessato (RODOTÁ, 2012. p. 256). 
Os bioconservadores sempre opuseram bastante resistência sobre a transcendência dos limites biológicos do ser humano, pois entendem que extrapolam os limites éticos, que a Ciência e a Medicina devem observar.

Avançando nas teorias do transumanismo e do pós-humanismo, o professor Rodotá ressalta que não houve apenas o surgimento de uma dimensão virtual do ser humano, com a Internet e a Inteligência Artificial, mas mudou-se a própria percepção da pessoa e de seu corpo. Em contrapartida, constatou a dificuldade de aceitação, pela sociedade, das inovações próprias da possibilidade de projetar a pessoa humana para uma nova dimensão. O termo "transumano" foi introduzido pelo biólogo Julian Huxley, em 1957, quando já afirmava que a "humanidade deverá transcender a si mesma” (RODOTÁ, 2003, p. 10).

O transumanismo é um movimento intelectual que parte do pressuposto de que a espécie humana ainda não chegou ao ápice de sua evolução. Baseia-se na utilização das tecnologias disponíveis para a superação das limitações biológicas do ser humano, como as doenças, o envelhecimento e a própria morte, ante o desejo de melhorar de modo substancial a condição humana, suas capacidades intelectuais e físicas, através da razão aplicada. Seria, portanto, uma fase de transição para um estágio muito mais avançado: o pós-humano (RODOTÁ, 2012. p. 342).

Para Rodotá “os transumanistas, e não apenas eles, veem na revolução científica e tecnológica a oferta contínua de um presente que deve ser plenamente explorado", referindose também à leitura do texto bíblico que vê "o mundo confiado à vontade do homem, portanto, legitimado a também intervir em si mesmo". ${ }^{9}$

No artigo publicado no jornal La Repubblica, em 11.06.2011, Rodotá cita as Magnalia Naturae de Francis Bacon (1627), no apêndice à Nova Atlântida:

\begin{abstract}
prolongar a vida; retardar o envelhecimento; curar as doenças consideradas incuráveis; aliviar a dor; transformar o temperamento, a estatura, as características físicas; reforçar e exaltar as capacidades intelectuais; transformar um corpo em outro; fabricar novas espécies; efetuar transplantes de uma espécie à outra; criar novos alimentos, recorrendo a susbstâncias não usadas hoje (RODOTÁ, 2011).
\end{abstract}

Prossegue no artigo, afirmando que o corpo humano se tornará um "campo de batalha planetário", na medida em que "se enfrentam a resistência de bioconservadores versus

9 I transumanisti e non solo loro, vedono nella rivoluzione escientifica e tecnologica l'offerta continua di un dono che deve essere interamente messo a frutto, richiamandosi anche a una lettura del testo bíblico che vede il mondo affidato alla volontá dell' uomo, legittimato dunque a intervenire anche su se stesso (RODOTÁ, op. cit. p. 286-287). 
as ideias dos transumanistas", sendo essa polarização inócua, em face da fase, inteiramente nova, na qual a humanidade já entrou: esse novo mundo tecnológico, que é muito mais do que uma referência habitual à distopia de Aldous Huxley. E recorda aquilo que Günther Anders indagava, em 1956:

como um pioneiro, o homem desloca as suas fronteiras sempre mais para lá, se afasta sempre mais de si mesmo; se 'transcende' sempre mais - e mesmo que não voe para uma região sobrenatural, no entanto, assim que cruza os limites congênitos da sua natureza, passa para uma esfera que não é mais natural, no reino do híbrido e do artificial (RODOTÁ, Stefano. Humanos e pós-humanos: os novos desafios da bioética. Tradução de Moisés Sbardelotto. Revista Eletrônica Instituto Humanitas Unisinos. 2011, p. 04).

E continua, afirmando que, "o corpo humano passará por uma completa transição, reclinando-se para o virtual, transformando-se numa nano-bio-info-neuro-máquina”, última versão daquele "homme machine" ao qual La Mettrie e D'Holbach se referiam, será cada vez mais reconhecido como uma prótese, com uma reconsideração das modalidades de definição do ser humano (RODOTÁ, 2011, p. 05). Isso já é uma realidade em relação à implantação de próteses endoesqueléticas de alumínio, que substituem o órgão amputado, restituindo a mobilidade ao indivíduo.

Rodotá colacionou o caso de Oscar Pistorius, um corredor sul-africano que, privado da parte inferior das pernas, substituída por implantes de fibra de carbono, teve reconhecido o direito de participar das Olimpíadas. Esse precedente proporcionou um tratamento igualitário entre os "normodotados", ou seja, os portadores de próteses, fazendo surgir "uma nova noção de normalidade, que não é mais apenas naturalmente determinada, mas, sim, artificialmente construída" (RODOTÁ, 2012. p. 314). Inspirando-se nesse episódio, outra atleta paraolímpica, Aimée Mullins, afirmou que "modificar o próprio corpo com a tecnologia não é uma vantagem, mas, sim, um direito. Tanto para quem faz esporte em nível profissional, quanto para o homem comum"(RODOTÁ, 2012. p. 314).

Já a teoria do pós-humanismo prega que nossos descendentes serão tão melhorados pela tecnologia, a ponto de não poderem mais ser chamados de humanos, serão verdadeiros cyborgs, por utilizarem próteses difusas, de várias naturezas e funções, que modificarão profundamente a funcionalidade orgânica, tornando pouco reconhecíveis as demarcações entre humanos e máquinas, entre mecanismos cibernéticos e biológicos. ${ }^{10}$

10 "Una piu sobria definizione del post-umano, che lo riferisce alla 'tecnologia che permette di superare I limiti della forma umana” (RODOTÁ, S., 2012. p. 344). 
Rodotá afirmava que os autômatos, "mecanismos engenhosos", nos fascinam desde a antiguidade, abrem caminho para outras criaturas mecânicas, como robôs e diferentes máquinas pensantes, "e então os cyborgs aparecerão, com o anúncio do trans e pós-humano", em pesquisas sobre as relações entre cérebro e máquinas, sobre 'interfaces cérebro-máquina' (IMCs) e, mais geralmente, sobre 'interação humano-computador' (HCI). ${ }^{11}$

Parece tema de ficção científica, mas já se fala da possibilidade de transferir as informações de um suporte a outro: a informação do cérebro pode ser extraída e introduzida em uma máquina, fazendo do corpo biológico uma sede ocasional. A Internet também poderia ser coligada ao cérebro por um implante neural (RODOTÁ, 2012. p. 314).

Alguns teóricos, como Raymond Kurzweil, acreditam que o ritmo das inovações tecnológicas vindouras será tão acelerado que, nos próximos 50 anos, podem surgir avanços tão radicais que poderão modificar, fundamentalmente, a natureza dos seres humanos (KURZWEIL, 2005, p. 102).

Todas essas questões são abordadas por Rodotá, no conjunto de sua obra, que resume afirmando o surgimento de uma "nova antropologia" (RODOTÁ, 2012, 340), sendo que estes conceitos servirão de base para a proposição que faremos a seguir.

\section{A questão do transplante de órgãos no Brasil}

Ao refletir sobre os conceitos de transumanismo e pós-humanismo, trazemos a lume um problema que aflige boa parte da humanidade, a saber: a demanda por transplantes de órgãos.

Somente no Brasil, mais de 45 mil pessoas aguardam na lista de espera por um transplante de órgãos, conforme dados da Sociedade Brasileira de Transplantes de Órgãos ABTO. Essa fila só tem aumentado, devido à pandemia de Covid-19 (MELO, 2020, p. 2).

Segundo dados da Revista Isto é (2020), desde que a Organização Mundial de Saúde (OMS) decretou a pandemia de Covid-19, em março de 2020, o número de transplantes foi reduzido drasticamente, com $34 \%$ menos, do que os realizados no mesmo período de 2019 . O presidente da ABTO, Hoygens Garcia, afirmou que a mortalidade na fila de espera também

11 Gli automi, $i$ "mecanismi ingegnosi" ci affascinano sin dall'anctichitá, aprono la strada ad altre creature meccaniche, come robot e le diverse macchine pensanti e poi verranno i cyborg, con il loro annuncio de trans- e del post-umano, le ricerche sui rapporti tra cervello e macchine, sulle 'brain machine interface' (BMIs) [...] e piú in generale sulla 'human computer interaction (HCI). (Ibid., p. 313). 
aumentou.

Diversos fatores contribuem para a redução da realização dos transplantes: 1) o risco de potenciais doadores e de pacientes transplantados (que já possuem status imunológico baixo), de se contaminarem com o Coronavírus; 2) a priorização do uso dos leitos de UTI's para os pacientes de Covid-19; 3) a redução de voos comerciais, que também serverm para transportar os órgãos; 4) a não autorização da família do potencial doador, por questões éticas e religiosas; 5) a redução do número de mortes por traumas encefálicos.

Nesse contexto, como o processo de doação de órgãos exige a observância de rígidos protocolos internacionais de segurança, foi acrescentado um novo protocolo, o de testagem do potencial doador, para saber se está infectado pelo novo Coronavírus. Como o exame PCR tem o resultado demorado, o doador que já teve morte encefálica permanece com o coração batendo e os órgãos vitais funcionando, com o auxílio de aparelhos e medicações. Porém, é um quadro de extrema instabilidade, com risco de parada cardíaca do doador e inviabilização da utilização dos seus órgãos para transplante.

Segundo dados da Revista Eletrônica Saúde em Debate (2020), a logística que envolve a captação e o transporte de órgãos, por via aérea, é outro fator que reduz o êxito dos transplantes: se não houver agilidade, o transplante não poderá acontecer, pois cada órgão tem um tempo máximo de duração fora do corpo, o coração, por exemplo, resiste por quatro horas.

Entretanto, segundo dados da própria ABTO (2020), não é a falta de estrutura, mas a negativa familiar o principal motivo para que um órgão não seja doado, no Brasil. De todas as mortes encefálicas, pouco mais da metade se transforma em doação. A principal justificativa das famílias para não doar órgãos é o fato de nunca terem conversado com o familiar, sobre o desejo de doar. Quando isso não é um assunto resolvido, cabe a uma equipe do hospital, responsável pela captação de órgãos, explicar à família que a morte encefálica já é morte. Quando ela é decretada, é porque ocorreu a parada definitiva e irreversível do cérebro e do tronco cerebral, o que provoca, em poucos minutos, a falência de todo o organismo.

A Constituição Federal reza que a lei deverá dispor sobre as condições que facilitem a remoção de órgãos e tecidos humanos para fins de transplante, sendo vedado todo tipo de comercialização $\left(\mathrm{CF} / 88\right.$, art. 199, § $\left.4^{\circ}\right)$. A Lei Federal no $9.434 / 97$ permite a disposição de tecidos, órgãos e partes do corpo humano, em vida ou post mortem, desde que de forma gratuita.

Os transplantes somente podem ser realizados por equipes médico-cirúrgicas 
previamente autorizadas e após a realização de todos os exames e testes de triagem no potencial doador. Somente os portadores de doenças progressivas, incapacitantes e irreversíveis podem ser submetidos a transplantes de órgãos, devendo haver o consentimento informado sobre as condutas médicas a serem realizadas durante o procedimento e quais os benefícios, sequelas e rejeições eventualmente esperados $\left(\operatorname{artigos} 1^{\circ}\right.$ e $\left.2^{\circ}\right)$.

$\mathrm{Na}$ retirada post mortem de tecidos, órgãos e partes do corpo humano, destinados a transplantes, deve haver o prévio diagnóstico de morte encefálica, constatada por dois médicos, não participantes das equipes de remoção e transplante, mediante a utilização de critérios clínicos e tecnológicos definidos por resolução do Conselho Federal de Medicina. É admitida a presença de médico de confiança da família do falecido, no ato da comprovação e atestação da morte encefálica (artigo $3^{\circ}$ e $\S 3^{\circ}$ ). Deve haver, ainda, a prévia autorização da família do doador, do cônjuge ou parente, maior de idade, até o segundo grau, inclusive, em documento subscrito por duas testemunhas presentes à verificação da morte (artigo $4^{\circ}$ ).

Vale destacar que a questão dos transplantes de órgãos é tratada, ainda, pelo direito transnacional, na medida em que os organismos internacionais buscam combater o lado sombrio dessa realidade, que diz respeito aos crimes de tráfico internacional de órgãos e tecidos, cometidos por quadrilhas internacionais. Nesse ponto, Rodotá já pregava a proibição de tornar o corpo humano e suas partes como uma fonte de lucro. ${ }^{12}$

A própria Lei Federal, $n^{\circ}$ 9.434/97, prevê como crimes as diversas condutas relacionadas com o tráfico de órgãos humanos, seja ele nacional ou internacional. As condutas descritas como criminosas são: remover tecidos, órgãos ou partes do corpo de pessoa ou cadáver, em desacordo com as disposições legais (art. 14); comprar ou vender tecidos, órgãos ou partes do corpo humano (art. 15); realizar transplante ou enxerto utilizando tecidos, órgãos ou partes do corpo humano de que se tem ciência terem sido obtidos em desacordo com a Lei (art. 16); recolher, transportar, guardar ou distribuir partes do corpo humano de que se tem ciência terem sido obtidos em desacordo com a Lei (art. 17); realizar transplante ou enxerto em desacordo com a Lei (art. 18); deixar de recompor cadáver, devolvendo-lhe aspecto condigno, para sepultamento ou deixar de entregar ou retardar sua entrega aos familiares e interessados. (art. 19); publicar anúncio ou apelo público por transplante de órgãos (art. 20).

O tema dos transplantes de órgãos é retratado como uma distopia, na obra de ficção do escritor Kazuo Ishiguro, Prêmio Nobel de Literatura em 2017, intitulada "Never Let Me

12 "[...] il divieto di fare del corpo umano e delle sue parti in quanto tali una fonte di profitto". [...] (RODOTÁ, S., 2012. p. 270) 
Go" (2005), bem como, no filme homônimo, com o título em português "Não me Abandone Jamais" (2010). A distopia é qualquer representação social, cujo valor representa a antítese da utopia ou uma "utopia negativa". Retrata um lugar, época ou estado imaginário em que se vive sob condições de extrema opressão, desespero e privação. As distopias são, geralmente, caracterizadas pelo autoritarismo e a tecnologia se insere nesse contexto como ferramenta de controle, por parte do Estado ou de instituições. Retratam a sociedade em um futuro próximo, onde os limites éticos são extrapolados ao máximo (JACOBY, 2007, p. 31).

A história do livro de Kazuo Ishiguro (2005) é ambientada em um idílico colégio interno, situado em uma província inglesa, em que as crianças internas descobrem, acidentalmente, que, na verdade, são clones de pessoas, criadas com o único objetivo de doarem seus órgãos para transplantes em outros seres humanos, até que a retirada sucessiva de partes dos seus corpos os leve à morte. A obra nos leva a uma profunda reflexão sobre os limites éticos que devem ser observados pela Ciência e pela Medicina, em relação às intervenções médicas no corpo humano, com consequências para a própria existência humana, notadamente quanto aos transplantes de órgãos, pois nem sempre os fins justificam os meios. A vida humana não deve ser sacrificada para suprir a necessidade de outro ser humano. Nesse sentido, a lei brasileira reprime a intervenção médica ou cirúrgica, sem o consentimento do paciente ou representante legal e com o fim de lucro.

Tampouco nos parece justo, por outro lado, que milhares de pessoas aguardem, indefinidamente, na fila de potenciais receptores de órgãos a serem transplantados de pessoas que sofreram mortes encefálicas, uma vez que tal espera tem ocasionado inúmeros óbitos.

\section{A bioimpressão como solução para o transplante de órgãos}

É nessa direção que vislumbramos como solução para a complexa questão acima tratada, capaz de trazer um alento para as milhares de pessoas, que aguardam na fila de espera por transplantes de órgãos, a bioimpressão 3D - uma técnica que é ramificação da engenharia de tecidos e da medicina regenerativa, que se dedica, desde os anos 80 , a produzir tecidos biológicos, em laboratório.

Atualmente, já existem protótipos de órgãos humanos, criados por impressoras 3D, com a finalidade de, futuramente, servirem de material para fins de transplante de órgãos. $\mathrm{O}$ uso da tecnologia de bioimpressão 3D para fazer órgãos, a partir de células-tronco do próprio 
paciente, poderá vir a ser a solução para o problema da rejeição por incompatibilidade com o sistema imunológico do receptor.

Segundo a Revista Bioemfoco (2017), a impressão 3D na área da saúde começou a ser usada para a produção de próteses de reconstrução óssea, na década de 80. Hoje, é possível a fabricação de tecidos da pele e cartilagens. Alguns órgãos também já começam a ser impressos, mas, por enquanto, apenas como protótipos, para auxiliar nas cirurgias. Um marco dessa tecnologia foi o desenvolvimento de uma orelha, nas costas de um camundongo, nos anos 90, imagem que rodou o mundo, pois ali estava a tridimensionalidade (VICENTE, 2020).

Em 2010, a start-up de biotecnologia Organovo imprimiu o primeiro vaso sanguíneo e posteriormente, lançou, no mercado, a primeira impressora de tecido humano. A empresa Cellink, por sua vez, já comercializa a "tinta biológica”, que é um líquido, ao qual as células humanas são misturadas e, então, impressas em três dimensões. A agulha da impressora rabisca uma placa de Petri, com tinta biológica, então é possível então ver uma orelha ou um nariz surgindo. A máquina imprime o órgão em três dimensões, depositando camada sob camada, as gotas de "biotinta", composta por hidrogel, uma espécie de gelatina, contendo células que se unem para formar a estrutura.

Pesquisadores do Instituto Federal de Tecnologia, de Zurique, na Suíça, utilizam a técnica para imprimir cartilagem, criada a partir da cultura do material genético do próprio paciente, reduzindo as chances de uma rejeição.

Em 2011, um pesquisador do Instituto de Medicina Regenerativa da Universidade de Wake Forest, nos Estados Unidos, proferiu palestra, apresentando um rim, impresso no dia anterior, num processo que levou sete horas. Afirmou que, por enquanto, é possível imprimir somente a carcaça do órgão, mas não sua parte interna. $\mathrm{O}$ método sinaliza o início de uma espécie de revolução industrial dos transplantes. Uma era em que pode ser possível produzir órgãos, em larga escala, até sob encomenda (PONTES, 2020, p. 03).

Em 2014, um estudo publicado na revista Nature revelou que pesquisadores norteamericanos conseguiram implantar tecidos, impressos em 3D, em animais. Os cientistas imprimiram estruturas cartilaginosas, ósseas e musculares e a transplantaram nos roedores. Essas células desenvolveram um sistema de vasos sanguíneos e se transformaram em tecidos (MURPHY, Sean. ATALA, Anthony. 2014).

Em 2019, uma equipe da Universidade de Tel-Aviv, em Israel, apresentou um 
protótipo de coração humano impresso: a estrutura contava com tecidos e vasos sanguíneos, mas era do tamanho de uma cereja. Ou seja, para que esse tipo de órgão seja útil aos humanos, falta muito. A vascularização ainda é precária, o material biológico para a impressão ainda não é suficientemente estruturado e, sobretudo, há dificuldades em fazer o órgão realizar suas funções principais - o minicoração israelense até bate, mas não consegue bombear sangue. É um protótipo. Os cientistas avaliaram que os pontos que ainda precisam de evolução são a multiplicação de uma quantidade suficiente de células cardíacas e o processo de maturação, pelo qual as células do novo coração poderão ser sincronizadas, provocar pulsações e, finalmente, permitir que o órgão funcione de forma autônoma (FOSTER, 2019, p. 5).

Portanto, ainda é um desafio reproduzir a vascularização e a enervação dos órgãos, por exemplo. O problema está no comportamento celular, ou seja, na interação entre a estrutura tridimensionalmente fabricada e o comportamento da célula (VICENTE, 2019, p. 07).

Segundo o Instituto de Pesquisas com Células-Tronco - IPTC, a pesquisa em bioimpressão de órgãos 3D vem sendo desenvolvida também no Brasil, por pesquisadores da Divisão de Tecnologias Tridimensionais (DT3T), do Centro de Tecnologia da Informação (CTI) Renato Archer, uma das unidades de pesquisa do Ministério da Ciência, Tecnologia e Inovação, localizada em Campinas/SP. Apesar de as pesquisas estarem ainda nos primeiros passos, acredita-se que, em menos de 20 anos, será possível produzir órgãos humanos em laboratório, para transplantes.

Assim, podemos concluir que diversos cientistas do mundo, estão trabalhando, atualmente, em pesquisas para aprimorar essa tecnologia de bioimpressão de órgãos 3D, a fim de reproduzir órgãos humanos, em laboratório, que sejam funcionais e sob medida, para cada um dos pacientes, potenciais receptores de órgãos. Isso mudaria, completamente, o cenário dos transplantes no mundo, ocasionando uma verdadeira revolução, capaz de salvar milhares de vidas.

Essa tecnologia, de impressão de órgãos humanos em 3D, possui estreita ligação com a bioética, pois representa o esforço humano, em ultrapassar suas limitações biológicas inatas, através da Ciência e da Medicina. Os futuros órgãos a serem produzidos em laboratório se encaixam no conceito de prótese e nas teorias do transumanismo e do pós-humanismo, tão bem abordadas pelo professor Rodotá, com potencial de prolongar a vida do ser humano e melhorar sua qualidade de vida, contribuindo para a formação de um novo ser humano, 
híbrído, biológico e artificial, ou seja, trans-humano.

\section{Considerações Finais}

O presente artigo buscou estudar a obra do professor italiano Stefano de Rodotá, sobre o desenvolvimento do conceito de autodeterminação do indivíduo, sobre a sua existência e o seu corpo, que encontra amparo no princípio constitucional da dignidade da pessoa humana $\left(\mathrm{CF} / 88\right.$, art. $\left.1^{\circ}, \mathrm{III}\right)$, em face das inovações tecnológicas e científicas da pósmodernidade, notadamente nas áreas da Ciência e da Medicina, através de tratamentos de saúde e tecnologias, que proporcionam o prolongamento artificial da vida ou a melhoria da qualidade de vida.

O problema central abordado foi o cenário dos transplantes de órgãos no Brasil, evidenciando-se que a fila de pessoas que aguardam um transplante de órgãos aumentou em face da pandemia de Covid-19, havendo grande probabilidade do aumento do número de óbitos de potenciais receptores de órgãos.

Propôs-se como solução para o problema, a bioimpressão de órgãos 3D, ou seja, de órgãos humanos artificiais, que serão verdadeiras próteses, criadas em laboratório, capazes de substituir os órgãos defeituosos.

Atualmente, essa tecnologia é objeto de pesquisas científicas, em vários países do mundo, inclusive no Brasil, com previsão que estará disponível em 20 anos. A proposta encontra amparo nas teorias do transumanismo e do pós-humanismo, relacionadas à bioética.

O transumanimo e o pós-humanismo são teorias que acreditam no desenvolvimento das capacidades físicas, mentais e intelectuais do ser humano, para um novo patamar de evolução antropológica, criando-se um ser humano híbrido, trans-humano. A bioética, por sua vez, deverá nortear os limites éticos desses avanços científicos e tecnológicos.

Assim, acreditamos ser essencial trazer a lume o pensamento do professor italiano Stefano de Rodotá, que abordou tão bem esses temas de vanguarda da pós-modernidade: Internet, bioética, transumanismo e pós-humanismo, pois sua obra serve de guia e inspiração para os cidadãos que ainda vivenciarão o futuro.

\section{Referências das Fontes Citadas}

A BIOIMPRESSÃO e a Engenharia de Tecidos. Revista eletrônica IPCT, (2018). 
Disponível em <http://celulastroncos.org.br/a-bioimpressao-e-a-engenharia-de-tecidos/> . Acesso em 05 ago. 2020.

BRASIL. Constituição da República Federativa do Brasil, de 05 de outubro de 1988. Brasília: Senado Federal, Subsecretaria de Edições Técnicas, 2008, 464 p.

BRASIL. Lei Federal $\mathbf{n}^{\mathbf{0}}$ 9.434, de 4 de fevereiro de 1997. Dispõe sobre a remoção de órgãos, tecidos e partes do corpo humano para fins de transplante e tratamento e dá outras providências. Disponível em <https://www.planalto.gov.br>. Acesso em 20 jun. 2020.

DINIZ, Débora. GUILHEM, Dirce. O que é Bioética. Brasiliense, São Paulo, 2002.

DONEDA, Danilo; ZAMATTA, Rafael A. F. Rodotá e o equilíbrio entre direito, tecnologia e política. Revista Eletrônica Jota. 28 de junho de 2017. Disponível em: $<$ https://www.jota.info/opiniao-e-analise/artigos/rodota-e-equilibrio-entre-direitotecnologia-e-politica-28062017>. Acesso em 15 jul. 2020.

FALTA DE CONHECIMENTO sobre a irreversibilidade da morte encefálica é principal causa de recusa de doação de órgãos. Revista Eletrônica da Associação Brasileira de Transplantes de Órgãos. 2020. Disponível em <www.abto.org.br/abtov03>. Acesso em 05 ago. 2020.

FOSTER, Gustavo. Impressão 3D na medicina: o que já existe e o que pode vir por aí. 04.07.2019. Revista Eletrônica Gaúcha AZ. Disponível em <https://gauchazh.clicrbs.com.br/saude/vida/noticia/2019/07/impressao-3d-na-medicina-oque-ja-existe-e-o-que-pode-vir-por-ai-cjxopjti603kq01pkdqx6q4s7.html>. Acesso em 05 ago. 2020.

IMPRESSÃO DE ÓRGÃOS EM 3D: O FUTURO DOS TRANSPLANTES?. Revista

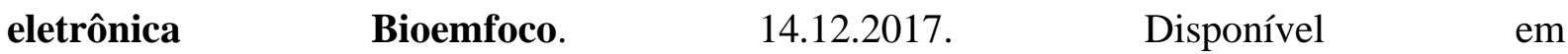
$<$ http://bioemfoco.com.br/noticia/impressao-orgaos-3d-futuro-transplante/>. Acesso em 05 ago. 2020.

ISHIGURO, Kazuo. Não me abandone jamais. Tradução de Beth Vieira. São Paulo: Companhia das Letras, 2005.

JACOBY, Russell. Imagem Imperfeita: Pensamento Utópico para uma Época Antiutópica. Rio de Janeiro: Civilização Brasileira, 2007, p. 31.

KURZWEIL, Raymond. The Singularity Is Near. When Humans Transcend Biology. Viking Adult. 2005. ISBN 0-670-03384-7. OCLC 224517172. Disponível em <https://pt.linkfang.org/wiki/Trans-humanismo>. Acesso em 10 ago. 2020.

MELO, Karine. Pandemia de Covid-19 diminui quantidade de transplantes no Brasil. Revista Eletrônica Agência Brasil. Brasília, 11.05.2020. Disponível em $<$ https://agenciabrasil.ebc.com.br/saude/noticia/2020-05/pandemia-de-covid-19-diminuiquantidade-de-transplantes-no-brasil >. Acesso em 29 jul. 2020.

MURPHY, Sean. ATALA, Anthony. 3D bioprinting of tissues and organs. Revista 
NatureBiotecnology. $\quad$ v. $32, \quad 773-785 \quad$ (2014). 05.08.2014. Disponível em <http://www.nature.com/journal/v32/n8/full/nbt2958.html>. Acesso em 05 ago. 2020.

NÚMERO DE TRANSPLANTES DE ÓRGÃOS NO BRASIL CAI 34\%. São Paulo. 26.05.20. Revista Isto é. Ed. 2637-24/07. Disponível em <https://istoe.com.br/numero-detransplantes-de-orgaos-no-brasil-cai-34/>. Acesso em 29 jul. 2020.

O IMPACTO do novo coronavírus no transplante de órgãos. Revista Saúde em Debate. 2020. Disponível em <https://saudedebate.com.br/noticias/o-impacto-do-novo-coronavirusno-transplante-de-orgaos>. Acesso em 29 jul. 2020.

PONTES, Felipe. Está mais próximo o dia em que você poderá pedir rim, bexiga e veias sob encomenda ou imprimi-los em 3D. Conheça as tecnologias que prometem uma revolução industrial dos transplantes. Revista Eletrônica Galileu. Disponível em $<$ http://revistagalileu.globo.com/Revista/Common/0,ERT220794-17773,00.html $>$. Acesso em 05 ago. 2020.

RODOTÁ, Stefano. In: Palestra proferida no Rio de Janeiro. 20 de março de 2003, p. 3. Traduzida para o português por Myriam de Filippis. Disponível em <http://www.rio.rj.gov.br/dlstatic/10112/151613/DLFE-

4314.pdf/GlobalizacaoeoDireito.pdf >. Acesso em 14 jul. 2020.

RODOTÁ, Stefano. Humanos e pós-humanos: os novos desafios da bioética. Tradução de Moisés Sbardelotto. Revista Eletrônica Instituto Humanitas Unisinos. 2011. Disponível em $<$ http://www.ihu.unisinos.br/noticias/44271-humanos-e-pos-humanos-os-novos-desafios-dabioetica>. Acesso em 20 jun. 2020.

RODOTÁ, Stefano. Il diretto di avere diritti. Roma-Bari, Laterza, 2012. ISBN 978-88-4209608-5.

SIQUEIRA, Mariana de. A inteligência artificial no Judiciário brasileiro. Revista Eletrônica Jota. 28.07.2020. Disponível em <https://www.jota.info/coberturas-especiais/inova-e-acao/ainteligencia-artificial-no-judiciario-brasileiro-28072020>. Acesso em 03 ago. 2020.

SOUZA, Carlos Affonso. O legado de Stefano Rodotá sobre direitos na Internet: um guia de referências. Revista Observatório da Internet. 27 de junho de 2017. Disponível em: $<$ https://observatoriodainternet.br/post/o-legado-de-stefano-rodota-para-o-debate-sobredireitos-na-internet-um-guia-de -referencias>. Acesso em 14 jul. 2020.

VICENTE, João Paulo. Já imprimimos órgãos humanos; bioimpressão 3D é futuro dos transplantes. Revista Eletrônica UOL. 20.09.2019. Disponível em <https://www.uol.com.br/tilt/noticias/redacao/2019/09/20/bioimpressao-o-futuro-nos-orgaoshumanos-impressos-em-laboratorio.htm>. Acesso em 05 ago. 2020. 